\title{
A saúde dos povos do mar: faróis para a Estratégia Saúde da Família em comunidades pesqueiras do Nordeste brasileiro
}

\author{
Sea people's health: lighthouses for the Family Health Strategy \\ in fishing communities in Northeast Brazil
}

Cleilton da Paz Bezerra (https://orcid.org/0000-0002-7196-534X) 1,2

Ângela Maria Bessa Linhares (https://orcid.org/0000-0002-1440-4407) ${ }^{2}$

${ }^{1}$ Secretaria de Saúde Pública do Rio Grande do Norte, Hospital Regional Tarcísio Maia. Rua Projetada $\mathrm{s} / \mathrm{n}$, Aeroporto.

Mossoró RN Brasil. cleiltonpaz@yahoo.com.br

${ }^{2}$ Universidade Federal do

Ceará. Fortaleza CE Brasil.
Abstract Sea people are culturally differentiated by their way of life intertwined with sea fishing and their social and symbolic production. In northeastern Brazil, these people have been changing their living conditions. The Family Health Strategy (ESF) should strengthen links with different cultures to meet its basic principles. We aimed to reflect on the challenges of the ESF in the context of sea people. We conducted ethnographic research in the community of Redonda, Icapui, State of Ceará, using dense descriptions constructed through the narratives of small-scale fishers and their families. We analyzed from the theoretical approach of studies in traditional communities. The results are shown in five themes: 1) The family has an extended dimension in communities established with relatives; 2) Fishing life temporalities govern the common acts of the land-sea dyad; 3) The shifts between being "native" and "outsider" create border areas that dialogue with the rituals of belonging; 4) Sea territorialization and the knowledge of experience; 5) The ESF in the arenas of struggles for environmental justice. Here, the production of health is reaffirmed as the production of sea people's life.

Key words Culture, Family Health Strategy, Ethnicity and Health
Resumo Os povos do mar são culturalmente diferenciados por seu modo de vida imbricado com a pesca marítima e com toda sua produção social e simbólica. No nordeste brasileiro, essas populações vêm passando por transformações em suas condições de vida. A Estratégia saúde da Família (ESF) precisa fortalecer vínculos com as diferentes culturas para atender aos seus princípios basilares. Objetivamos refletir sobre os desafios da ESF no contexto dos povos do mar. Realizamos uma pesquisa etnográfica na comunidade de Redonda, Icapuí, Ceará, recorrendo às descrições densas construídas por meio das narrativas de pescadores artesanais e seus familiares. Analisamos a partir da abordagem teórica dos estudos em comunidades tradicionais. Os resultados são apresentados em cinco temas: 1) em comunidades constituídas por parentes, a família tem uma dimensão alargada; 2) as temporalidades da vida na pesca regem os atos comuns da díade terra-mar; 3) os deslocamentos entre ser "nativo" e ser "de fora" criam zonas fronteiriças que dialogam com os rituais de pertencimento; 4) a territorialização do mar e os saberes da experiência; 5) A ESF nas arenas das lutas por justiça ambiental. Reafirma-se aqui a produção da saúde enquanto produção da vida dos povos do mar.

Palavras-chave Cultura, Estratégia Saúde da Família, Origem étnica e saúde 


\section{Introdução}

Povos e comunidades tradicionais foram caracterizados pela Política Nacional de Desenvolvimento Sustentável como grupos que se reconhecem por suas culturas diferenciadas, cujas formas de organização social estão intimamente associadas à ocupação de territórios e recursos naturais que, por sua vez, se tornaram indispensáveis para a reprodução cultural, social, religiosa, ancestral e econômica desses povos e comunidades. Os espaços ocupados por eles são denominados de territórios tradicionais ${ }^{1}$.

Sabemos das ambiguidades que o termo tradicional carrega ${ }^{2}$. No entanto, utilizamos como um conceito de inegável potência enquanto estratégia política, ao destacar a história social de comunidades invisibilizadas em suas lutas, na relação com o ambiente em que vivem e onde constroem suas bases culturais. Além do que, o desenvolvimento e a operacionalização de políticas públicas que atendam aos reclamos dessas populações resultam por ser questão fundamental em saúde coletiva ${ }^{3}$. Nessas trilhas, as tensões expostas na relação saúde e ambiente, cujo nervo vivo vai encontrar lugar no escopo de atuação da Estratégia Saúde da Família (ESF), alcançam maior gravidade no solo de conflitos ambientais que envolvem grupos que usam, conferem significações e se apropriam diferentemente dos territórios ${ }^{4}$.

A pesca, muito anterior à colonização brasileira, é prática bastante comum aos indígenas e foi essa atividade que contribuiu para dar face singular às inúmeras culturas litorâneas regionais, dentre as quais destacam-se: a do jangadeiro, em todo o litoral nordestino, do Ceará até o sul da Bahia; a do caiçara, no litoral entre o Rio de Janeiro e São Paulo; e o açoriano, no litoral de Santa Catarina e Rio Grande do Sul ${ }^{5}$. A cada lugar desses povos do mar ter-se-á feição cultural característica.

O Nordeste brasileiro possui, em sua composição étnica, diversas comunidades e povos tradicionais que foram se formando principalmente a partir de remanescentes indígenas e escravos negros fugidos dos engenhos e do sistema escravocrata dos colonizadores europeus e que fizeram dos territórios livres lugares de trabalho e vida ${ }^{6}$. É o caso das comunidades pesqueiras marítimas ao longo da costa do Ceará que, ao ocuparem terras então abandonadas, passaram a ter na pesca artesanal a possibilidade de sobrevivência longe dos centros comerciais das capitanias ${ }^{7}$, contudo, sem deixar de compor as rotas que, margeando o Rio Jaguaribe, percorriam o caminho do sertão ao mar no comércio do charque ${ }^{6}$. São essas comunidades que, no presente texto, denominamos povos do mar, pois fizeram dos espaços litorâneos territórios de reprodução cultural, social, econômica e simbólica com características muito particulares ${ }^{8}$.

Pensar a saúde dessas populações implica subverter a lógica dos modelos de atenção que não atentam para as especificidades culturais existentes num país de dimensão continental como é o Brasil. Requer, sobretudo, a análise das especificidades históricas e das diferenciações internas que compõem as múltiplas realidades sociais, com fins à devida contextualização dos sujeitos, tendo em vista que as formas como as sociedades experimentam seus fenômenos de saúde e doença se reverberam no modo como estruturam seus enfrentamentos?.

Sabemos que a ESF, com a incorporação dos atributos essenciais da Atenção Primária à Saúde, tais como primeiro contato, longitudinalidade, integralidade e coordenação da atenção ${ }^{10}$, tem possibilitado, desde a sua expansão iniciada na década de 1990, uma grande imersão de profissionais da saúde nos territórios mais longínquos. Adentrar a esses contextos tem impelido esses profissionais ao diálogo com uma pluralidade de saberes. Nesse processo, tornou-se primordial à ESF perceber esses territórios como lugares da vida em movimento ${ }^{11}$, em que as experiências dos sujeitos individuais e coletivos, assim como suas diversas relações socioculturais, permeadas por conflitos e contradições, significam matéria -prima para nortear ações em saúde.

Deste modo, objetivamos refletir sobre os desafios da ESF no contexto dos povos do mar. Apostamos, assim, no diálogo que confere lugar de sujeito ao Outro e que supera a condição de silenciamento ${ }^{12}$ a que as populações periféricas são submetidas quando suas vidas são invisibilizadas perante processos violentos de apagamento de suas culturas no mundo globalizado.

A afirmação da saúde dos povos do mar indica a necessária pluridimensionalidade do sujeito humano e seu aspecto relacional, que criam as condições para a produção da saúde, como se vem discutindo desde a Primeira Conferência Internacional sobre Promoção da Saúde e da sua fecunda Carta de Otawa, de 1986, quando se reafirmou a saúde enquanto resultante das condições de vida ${ }^{13}$. 
Estudo qualitativo que utilizou a etnografia enquanto uma descrição densa ${ }^{14}$, ou seja, valorizando a escuta à fala dos sujeitos em seus contextos de vida, sem que o pesquisador se exima de sua implicação, sua possibilidade analítica, ao capturar narrativas plurais, que expõem o simbolismo desejante da cultura e o modo como confere significação às experiências, produzindo a viabilidade da vida social.

Para as análises das narrativas, enquanto fenômeno intersubjetivo, foi primordial a presença dos pesquisadores no campo de estudo, com profunda imersão no cotidiano dos sujeitos da pesquisa. $\mathrm{O}$ estudo foi realizado na comunidade de Redonda, no município de Icapuí, no extremo leste do litoral cearense, nos limites com o Rio Grande do Norte, a duzentos quilômetros de Fortaleza, inserida na microrregião do Baixo Jaguaribe. O motivo principal dessa escolha deu-se ao fato da referida comunidade ser reconhecida regionalmente por sua história de lutas populares em defesa da pesca artesanal e de combate a pesca predatória, características essenciais para sua autoidentificação enquanto povos do mar.

A etnografia foi realizada por um período de um ano em que operamos os seguintes procedimentos: observações participantes, elaboração de diários de campo, descrições densas de situações sociais, realização de entrevistas com informantes-chave e levantamento de genealogias. Todos foram realizados no ambiente onde os sujeitos vivem e produzem suas relações sociais, fazendo uso de aparelho de gravação de voz e cadernos de anotações, buscando apanhar os modos de compreensão desses contextos e dos fenômenos que nele se inserem.

Entendemos a pesquisa qualitativa como uma espécie de epistemologia da pergunta, significando que levanta e trata questões muito mais que lavra respostas previstas, aprofunda-se o dizível e mergulha-se no indizível processo da prática pesquisadora. As articulações e delineamentos críticos advém do mundo intersubjetivo que se extravasa, recobrindo o objetal acento que coloca os pesquisados como coisa (não por acaso são "objetos de estudo", como os sujeitos da saúde são "pacientes"), o que resulta por tornar, em certa medida, os textos acadêmicos discursos que escondem seus sujeitos.

Entre os informantes, tivemos pescadores, marisqueiras, idosos, professor, agente comunitário de saúde, artista popular e líder comunitário, numa faixa etária de 30 a 78 anos. Utilizamos codinomes (nomes de peixes) na identificação das falas dos participantes.

Partilhando com esses sujeitos as lidas do mar e do cotidiano da comunidade, pudemos arregimentar aquilo que Halbwachs ${ }^{15}$ chamou de memória coletiva trazendo, a partir da história singular, quadros sociais com suas temporalidades vívidas na lembrança. É que na rememoração há uma remessa permanente do sujeito ao seu grupo, porquanto a memória é composta por um conjunto perceptual que passa pela pessoa, e, se envolve a complexidade do sujeito, articula-se à experiência coletiva, pois que no auditório social evocado a pessoa invoca os outros de seu passado como avalistas.

Como num trajeto de viajantes antigos, mas vivências-reconhecimento, vimos os possíveis do esperançar e as partes lacunosas, compondo a rota de um caminho em que cada narrador, na fronteira de quem viveu um tempo que, mirado agora pelo presente, o reconstrói. Nesse processo, o experienciar se transmuda em produção de saber, na medida em que, como para Josso ${ }^{16}$, "vivências atingem o status de experiência a partir do momento em que fazemos um certo trabalho reflexivo sobre o que se passou e sobre o que foi observado, percebido e sentido"16(p.48).

Assim, no concerto das experiências dos povos do mar, construímos categorias que puderam trazer reflexões sobre a produção da saúde do lugar; exercício onde a memória faz-se arte de posicionar-se ante o que se conta e se reconhece como sentido e história que pede para ser continuada ${ }^{17}$. O percurso da análise urdiu-se, então, mediante a tessitura da própria etnografia, já que esta não visa apresentar os fatos como coisas, mas procurando desvelar suas vinculações internas, de modo que possibilite uma interpretação aos pesquisadores ${ }^{14}$.

Durante o processo, na leitura das narrativas se desvelava interfaces entre as práticas sociais dos sujeitos e os processos de produção da saúde, como da doença, envolvendo-se contextos e outros sujeitos, em uma intersubjetividade ativamente produzida. Denominamos de faróis às formas expressivas que condensaram temas, resultados de discussões e estudos. A metáfora alude, também, às luzes que indicam a chegada à terra, vindo do mar e que acendem para a ESF quando da elaboração das necessidades e proposituras da partitura conjunta, que afirma a luta por saúde do povo de Redonda.

Respeitamos os aspectos éticos da pesquisa que envolve seres humanos, sendo aprovado por Comitê de Ética e Pesquisa da Universidade Federal do Ceará. 


\section{Resultados e discussão}

Partimos aqui de uma ideia de cultura não apenas como as objetificações do mundo cotidiano, que se separa das formas como as pessoas constroem o mundo e lhes vão dando sentido, mas concebida como construto experiencial humano, como um devir, um processo permanente de formação ${ }^{18}$. Por esse prisma e diante da massa de memórias, de histórias de lutas pelo território, projetamos faróis que possam orientar a afirmação da saúde como bem comum e como afirmação da vida dos povos do mar.

\section{Farol: Em comunidades constituídas por parentes, o conceito de família tem uma dimensão alargada}

Há cerca de 2.228 pessoas morando atualmente em Redonda, pela contagem dos agentes comunitários de saúde. A maioria das famílias depende da pesca da lagosta, maior atividade econômica local. Entre outras atividades, há a pesca de peixe, os pequenos plantios dos agricultores familiares, os comércios e os serviços públicos. De acordo com a associação local de pescadores artesanais, somam-se 529 pescadores, constituindo-se na maior comunidade de pesca artesanal do Ceará.

No entanto, apesar do acentuado crescimento da comunidade, foi importante reconstituir alguns aspectos do processo de povoamento do lugar para se compreender algumas questões preciosas para a Estratégia saúde da Família, como é o conceito de família e como este pode ser mobilizado no contexto dos povos do mar:

Nós viemos de três famílias: os Crispins, os Corrupios e os Pindus. Aqui tinha bem pouquinha casa, de taipa, em cima dos morros, era só mata e coqueiral. Aí um rapaz de uma família começou a carregar a moça de outra, eles fugiam, aí misturou essas três famílias. E assim foi crescendo o lugar (...) Fransquinha, que era filha do primeiro casamento do velho João Crispim, começou um namoro com Pedro Currupio. Mas aí, o que aconteceu foi que Pedro Currupio roubou Fransquinha da casa do pai dela. Isso gerou uma desavença medonha, passaram muitos anos nessa intriga, nessa briga de família. Só foi melhorar essa rixa quando nasceu o filho deles, de Pedro com Fransquinha, que foi Antônio Rodrigues, que é meu avô. (Ariacó)

A noção de etnia é um construto sociopolítico e um grupo étnico, conforme Barata ${ }^{19}$, é definido em virtude de suas características socioculturais. O povoamento de Redonda, como se vê na fala de Ariacó, foi levando a formação de uma comunidade que se constituiu a partir de três grupos familiares: Crispins, Currupios e Pindus. Essa vinculação entre parentes vai ter sua importância no engendramento das lutas do lugar e no fortalecimento do sentimento de pertença à comunidade de Redonda.

Percebemos que a definição de família, nesse contexto, tem uma dimensão alargada para além da noção de familiar nuclear, pois incorpora a dimensão comunitária e aproxima-se com o conceito trago por $\operatorname{Dias}^{20}$ que se refere a um "grupo de pessoas que convivem, têm laços intensos de proximidade e compartilham o sentimento de identidade e pertencimento, que influenciarão, de alguma forma, suas vidas"20(p.221). A ESF é considerada um modelo de Atenção Primária à Saúde com foco na unidade familiar ${ }^{21}$. Em se tratando dos povos do mar, é primordial perceber que a unidade familiar extrapola as paredes de uma residência, assumindo proporções comunitárias, como vemos em Redonda.

Ao levantarmos as genealogias, nos perguntávamos: que reconfigurações são necessárias ao trabalho da ESF em contextos onde família e comunidade se confundem nas malhas de um pertencimento étnico?

\section{Farol: As temporalidades da vida na pesca regem os atos comuns da díade terra-mar}

Os moradores de comunidades ou aldeias de pescadores se vinculam a tempos e espaços movimentados por marés ou por ciclos de pescagem e trabalho, onde a natureza e a vida do mar estão sempre presentes:

Antigamente, aqui não tinha estrada, então só entrava em Redonda quando a maré estava seca. Ainda hoje, se o sujeito é pobre ainda é assim. O transporte tem suas horas e sua carestia. Se quisesse vim na maré cheia, tinha que ser de barco, pelo mar (...) Mas hoje, mesmo com as estradas, a gente ainda depende da maré pra fazer muita coisa, porque se ela tiver cheia não dá pra caminhar na praia, não dá pros meninos jogarem, não dá para povoar espaços (...) Pra pescar nas pedras, tem que ser maré de pedra, bem sequinha (...)E tem o tempo do paradeiro, que não pode pescar peixe nem o lagosto. A vida da gente tudo muda (Guarajuba).

Pelo depoimento de Guarajuba, pode-se aferir que essas populações organizam suas vidas junto a características ambientais, como os fluxos das marés e os períodos da desova dos animais marinhos, de tal modo que não se pode separar uma geografia física da feição humana e cultu- 
ral que caracteriza a vida do lugar. Portanto, se as atividades sociais estão atreladas à pescagem e ao movimento das marés, a observação desse aspecto é essencial para o planejamento de ações nessas comunidades, como bem percebe nossa narradora:

Porque eles pedem para que os hipertensos e diabéticos caminhem na praia três vezes por semana. Mas só que tem semana que a maré seca tá no pique do meio dia, no sol quente, então o povo não vai caminhar... Eles só caminham quando a maré baixou, tá seca, de tardezinha ou de manhã cedo, né? Daí tem os afazeres outros, a rolada da jangada, o conserto do peixe, o lagosto e sua venda, ou coisas assim que só vivendo aqui.... O ganho da vida garante a comida e a sustança... (Guarajuba).

Os tempos da pesca também definem muito o modo como essas populações se organizam. A pesca artesanal da lagosta não acontece o ano todo, ela tem um período conhecido como "paradeiro", como se viu mencionado antes por Guarajuba. Nesse tempo, não é permitida a captura desse crustáceo com fins de preservação da espécie, em sintonia com seu ciclo de procriação. É uma normativa da legislação pesqueira que os pescadores artesanais precisam seguir e, em contrapartida, recebem um seguro-defeso.

O "paradeiro" coincide com as chuvas dos primeiros meses do ano e as famílias, em sua grande maioria, alternam a pesca com atividades agrícolas, como os pequenos plantios típicos da agricultura familiar de subsistência:

A gente planta feijão, mandioca, milho, melancia, jerimum (...) Quando passa o inverno, começa os cajus, a gente faz mel, doce, vinho, assa castanha, vende, faz um dinheirinho e tudo. Porque vai precisar pra ajeitar os botes, comprar o material pra fazer os manzuás, pra abastecer as quimangas de farinha, de bolacha, de coco pra fazer o pirão de peixe (risos). De primeiro, a gente fazia muito era labirinto, tinha serão nas noites de lua cheia, aquela cambada de gente trabalhando nas grades de labirinto... (Galo do Alto).

A temporalidade cíclica regida pelo fluxo do mar e dos tempos das colheitas rege a vida desses povos de tal modo que não é possível produzir saúde nesses territórios sem a devida adequação das ações ao movimento que pulsa na vida cotidiana em interação com o ambiente e o trabalho e que se faz na díade terra-mar. Como bem define o pescador: "quando a gente não tá no mar, tá nos matos".

\section{3o Farol: Os deslocamentos entre ser "nativo" e ser "de fora" criam zonas fronteiriças que dialogam com os rituais de pertencimento}

Ao observar conversas dos moradores de Redonda, reunidos em uma barraca na praia conhecida como "Boca do povo", aconteceu que uma jovem menina do lugar passou de biquíni de banho e eles assim comentaram: "ela só quer ser de fora”. Imediatamente registramos essa expressão "ser de fora" em nossas anotações e passamos a refletir sobre seus sentidos e significados. Esse modo de falar, utilizado em várias oportunidades no dia a dia da comunidade, faz subentender que há uma compreensão implícita sobre o que é "ser de dentro", que há um conjunto de comportamentos, ações, atitudes, símbolos que Redonda reconhece como sendo parte dela, ou seja, da sua cultura em distinção com as demais.

A instabilidade e a fluidez das águas do mar e de seus recursos se relacionam fortemente com as práticas sociais e modos de vida desses povos. Estudos de antropologia marítima ${ }^{22}$ reforçam que as práticas socioculturais da gente do mar são marcadas, de maneira original, por essas propriedades naturais do mar, que marcam os aspectos técnico, simbólico, social, econômico e ritual dessas comunidades.

É nesse sentido que Diegues ${ }^{23}$ fala de cultura maritima ou maritimidade para se referir ao conjunto de várias práticas, não só econômicas, resultantes da interação humana com o espaço marítimo. Não se refere ao mundo oceânico só como entidade física, mas como produção social e simbólica. Ele ressaltou o particularismo do que chamou "gente do mar" 24 , seu modo de vida específico marcado por práticas sociais e culturais diferenciadas, por exemplo, das vidas camponesas.

Nos rituais de cura de Redonda, o mar comparece como sagrado nos ritos de rezas. A curandeira pronuncia orações em que se sussurra: "vai pras ondas do mar sagrado", conferindo ao oceano a capacidade de afogar todos os males que acometem suas vidas. No ritual dessa curandeira, observamos que ela virava a cabeça da criança em direção ao mar, num movimento rítmico de acalanto. No balanço do seu corpo, reproduzia o balanço das águas e, em comunhão com o ecossistema marinho e com a crença advinda dos seus convives, se arrebatava de poder e cura. 
Também em meio aos processos produtivos que se desenvolvem nas comunidades pesqueiras, empreendem-se muitos rituais e festejos. Vejamos as narrativas a seguir:

O que eu mais lembro era quando as porteiras se abriam para os burros entrarem, carregados dos feixes de mandioca. Era uma alegria muito grande para todo mundo. Mãe Chiquinha era a cevadeira, ela só cevava cantando. Lembro da música dela que dizia assim: "Mandioca, mandioca, macaxeira, eu quero fazer comer na boca da cevadeira". Quando estava perto de acabar a desmancha, tinha umas festas grandes. Da praia dava pra escutar os gritos dos trabalhadores lá dentro dos cajueiros, cantando, dando gritos, batendo palmas, rezando... (Ariacó).

A procissão de Nossa Senhora dos Navegantes é pelo mar. Os pescadores devotos de Nossa Senhora acompanham a procissão com seus barcos. $\mathrm{Na}$ frente vai o barco com a santa, quem levava a santa era o finado Pedro, que a mãe dele, Tia Germana, tinha um voto com Nossa Senhora pra proteger os filhos dela na pescaria e nenhum mal acontecia no mar (Arraia).

Mesmo que nos tempos atuais a biomedicina seja hegemônica nos modos como dita a atenção em saúde, importa enfatizar que a assimilação de ritos e saberes de cura se encontra difundida nos diversos espaços sociais que compõem os territórios dos povos do mar. Adverte Valla ${ }^{25}$ que "tenhamos cuidado em nossas interpretações das ações das classes populares e sua relação com a religião"25(p.162). Para muitos, essas práticas podem ser vistas como um ato de "carência", sem considerarem que podem vir a ser de "intensidade". Assim analisa: "o que pode ser visto como tentativa de resolver exclusivamente um problema material, poderia bem ser o resultado da vontade de viver a vida de uma maneira mais plena ou intensa"25(p.162).

Turner $^{26}$ conferiu ao ritual uma função de reconstrução e não somente de puro reflexo da estrutura social, como utilizavam os antropólogos funcionalistas. Nesse caminho, Linhares ${ }^{27}$ vê o ritual como reelaboração criativa, como potência para fundar o novo no seio da vida coletiva. Em suas palavras, os rituais são "um tipo de ação que lida com o simbólico e que se dá na interação social, manifestando-se, neles, a ambivalência do que é intenção com o que se efetivou no cotidiano"27(p.47).

Como a ESF poderia incorporar uma terapêutica que envolve a espiritualidade e a ritualidade nos processos de cuidado e cura?

\section{$4^{\circ}$ Farol: A territorialização do mar e os saberes da experiência}

$\mathrm{Na}$ lida com a pesca artesanal, os povos do mar mobilizam um saber-fazer produzido dentro de uma coletividade que se caracteriza por formas diversas de colaborações e parcerias no trabalho. Tupinambá ${ }^{28}$ ao expor a pesca artesanal enquanto atividade humana que é trabalho e expõe contradições do sistema maior, observa, contudo, a cooperação entre grupos e entre membros de uma tripulação, assentada na existência de um ethos que permite aos pescadores lidarem com desafios diários, dentre os quais os que envolvem risco. Ela entende que esse ethos é pressuposto para o desenvolvimento da atividade pesqueira e embasa a vida em comunidade.

Nesta prática solidária e grupal, a pesca artesanal mobiliza saberes ancestrais. $\mathrm{O}$ pescador artesanal, quando em alto mar, toma como referência, para guiar-se, os relevos que as paisagens desenham em sua vista. Esse saber de navegação e mestrança é transmitido de geração a geração. Os pescadores tomam a terra como referência e realizam marcações ou, em outras palavras, constroem lugares no mar, territorializam, como podemos ver na narrativa do pescador de Redonda:

A direção eu me baseio por um cajueiro alto que dá para ver lá do fundo do mar. Lá do fundo, esse cajueiro fica como uma moitinha bem miúda. Porque é assim, lá do fundo, a terra parece uma linha plana, então as moitinhas dos matos servem de direção. Dá para ver uma caixa d'água grande que tem lá em Aracati. Ela serve para gente marcar a profundidade que a gente está. Indo de mar a dentro, a gente tem que saber o local bom de pescar. Quem não souber, sai dizendo que o mar estava ruim. Mas não estava, é porque tem que saber onde estar, se está em Morro Vermelho, que a gente chama assim porque de lá dar para ver um morro alto e vermelho que tem para as bandas ali da Fontainha ou do Retirinho; tem também a Restinga, Cabeço, Primeiros Bancos, Segundos Bancos, tudo isso em alto mar. Se você não souber onde está, como a pescaria pode prestar? Vai sair dizendo que o mar tá ruim (Camurupim).

Essa divisão e apropriação do espaço em mares também é estabelecida pela profundidade, incluindo aí as características do relevo submarino, das correntes de água e os tipos de peixe que são possíveis de serem encontrados nesses locais. Percebeu Maldonado ${ }^{29}$ que a indivisão do meio, na ausência de marcos visíveis ou termos formais de posse, conduz os pescadores a esforços cognitivos 
e de elaboração da territorialidade que lhes são específicos. Assim, os pescadores, fazendo uso de saberes antigos e moldados pela experiência de vida, constroem territórios no alto mar. Ao demarcarem, realizam formas de apropriação subjetivas desses saberes e, também objetivamente, se formam mestres de pesca.

Para a ESF poder dialogar com esses saberes que se clareiam a partir da pesca artesanal, é primordial perceber que crianças, jovens, adultos e idosos interagem nos espaços da vida comum onde se dá uma aprendizagem pela socialização da cultura dessas comunidades ${ }^{30}$. Os espaços do aprender estão difusos em todo meio social e, no contexto dos povos do mar, a escola também é a aldeia, onde os "saberes de experiência feitos"12 são compartilhados e reproduzidos por gerações. O costume também se faz a partir de novas reinvindicações de direitos e assunção de formas de socialização de saberes.

E que também deve importar à ESF um certo descolamento do vivido, de modo a operar com a inserção no espaço público, enquanto lugar de produção e socialização de saberes em trânsito, a alcançar temporalidades e espaços diversos em diálogos permanentes. Essa compreensão é fundamental para a realização de práticas em saúde coletiva, porquanto geralmente os movimentos de educação popular têm observado a produção de saber nos espaços populares, o que vai requerer a superação dos moldes bancários (caracterizados por práticas assimétricas, onde não há escuta à população), tendo em vista que nessas comunidades os adoecimentos, sofrimentos e cuidados são percebidos como experiências humanas e compartilhadas, afirmadas no complexo maior da produção da vida social ${ }^{31}$.

À ESF, como bem atestou Silva ${ }^{32}$, cabe travar um exercício de contínua territorialização enquanto ativação frequente da vida que pulsa, onde se identifique situações-limite que obstacularizam a produção da saúde dos diferentes territórios. Nesse caminho, os aprisionamentos dos profissionais em discursos cristalizados e paralisantes precisam ser desterritorializados com vistas a possibilitar novos trânsitos e agenciamentos, em que os saberes que a própria comunidade oferece sejam articulados aos processos de trabalho da Saúde da Família.

\section{Farol: A ESF nas arenas das lutas por justiça ambiental}

A pesca vem sofrendo mudanças profundas. A lógica da indústria pesqueira com base empre- sarial passou a ser bastante incentivada no Brasil em meados do século XX. Na década de sessenta, o governo federal passou a conceder incentivos fiscais e várias empresas foram criadas no litoral brasileiro com vistas ao mercado internacional. No Ceará, por exemplo, surgiram várias empresas para exportação da lagosta que tiveram seu auge na década de setenta, mas que, por conta da sobrepesca, que foi extinguindo os recursos ambientais, e da recessão econômica no país, passaram por uma grave crise financeira ${ }^{5}$.

A prática da pesca artesanal, que sempre utilizou a propulsão natural como a vela ou o remo, que usa instrumentos e embarcações construídos artesanalmente e que realiza um trabalho de base familiar se viu ameaçada pela pesca industrial de larga escala. Esses interesses capitalistas repercutiram fortemente na intensificação da pesca predatória da lagosta e, consequentemente, na escassez da espécie ${ }^{28,33,34}$.

Nesse contexto de crise ambiental e, especificadamente de "crise da pesca", a luta dos povos do mar passou a se definir em torno da defesa da pesca artesanal. Diversos movimentos de resistências e organizações sociais se proliferam nas comunidades de pescadores, reafirmando a luta de um povo em defesa do seu território e seus modos de viver nele, como aconteceu em Redonda (Icapuí), Prainha do Canto Verde (Beberibe) e Batoque (Aquiraz) ${ }^{33-35}$. Diante disso, esses cenários têm sido lócus de diversos conflitos, conforme nos conta o pescador Cação:

Até a metade do século passado, a gente só pescava pra comer, pro alimento da família, ou para trocar por farinha, por sal (...) Quando começou o comércio da lagosta, tudo mudou, foi aquela ganância por dinheiro e tudo mais. Nos anos oitenta, por aí, apareceram os cafanguistas de vários cantos afora, os mergulhadores, eles abriam nossos manzuás e roubavam nosso pescado. Nós não aguentamos aquela injustiça, foi uma revolta danada, teve guerra, tiroteio e tudo dentro do mar, as lanchas deles foram queimadas, morreu gente... (Cação).

A partir de então, as formas de relação com o ambiente foram deixando de ser formas relativamente sustentáveis e controladas, para serem formas que envolviam os "de fora" que não reconheciam seus direitos. $\mathrm{O}$ conflito ambiental passou a se posicionar, então, como um estado permanente de usurpação dos direitos de vida das culturas tradicionais, dentre elas, as dos povos do mar. Embora esse processo encontre sempre resistências, os pescadores refletem que o viver da pesca passa por um "tempo difícil", atravessado pela falta de uma política ambiental que possa se 
posicionar fora do jogo dos grandes investimentos empresariais, que se inscrevem como política de Estado:

Depois a lagosta foi minguando, foi minguando... O que era uma fartura de esbanjar, hoje é quase desaparecida. Veio o povo de fora, o comércio da lagosta virou um ouro. Tanto de riqueza como de matança. Hoje ainda existe o comércio de lagosta na comunidade, mas não existe compensação, lucro para o pescador daqui. Só prejuizo para fazer bote e manzuá. Tem gente que não pega nada. $O$ tempo tá difícil para nós. Tem pescador que só ainda insiste pra garantir mesmo o seguro-desemprego no paradeiro, porque lagosta ele não pega não (Cação).

A percepção do valor de mercado da lagosta parece ter condicionado a saída de uma forma de vida onde se pescava para o sustento da comunidade e se trocava o essencial, para um outro modo de viver em que comercializar seria a finalidade primeira da pesca. Ao lado dessa mudança no valor do pescado e sua forma de apropriação, foi se delineando movimentos de transformação nas relações humanas e na esfera simbólica.

Por outro lado, a luta dos pescadores de Redonda se consolidou fortemente em defesa da prática exclusiva da pesca artesanal em áreas delimitadas por órgãos públicos responsáveis, como também pela fiscalização do cumprimento da legislação vigente, como o uso de equipamentos sustentáveis, respeito aos tempos de pescar e de preservar e aos tamanhos mínimos do crustáceo exigidos para sua captura: "não é pra pegar lagosta miúda"; "não é pra pescar lagosta no paradeiro"; "não é pra pescar de rede nem de marambaia pois destroem o meio ambiente, só de manzuá" - expõem eles suas pautas reivindicatórias.

Pensar sobre essas transformações que se deram no âmbito da pesca tornou-se fundamental para compreender a saúde coletiva desses povos. Como a crise na pesca reverberou nas condições de vida e saúde dessa população? Tendo em vista que o sistema público de saúde no Brasil está fundamentado nos direitos sociais expressos na Constituição Federal de $1998^{36}$, como construir alianças com as lutas dos povos do mar por seus direitos fundamentais?

No caso das comunidades tradicionais, há uma necessidade de uma agenda da equipe que se volte para a noção de "justiça ambiental" ${ }^{37}$, que designa um quadro de vida futuro que supere a desproporcionalidade dos riscos ambientais que atinge com maior impacto às populações pobres. A aliança com as lutas das populações tradicionais não significa que não se perceba suas con- tradições. É necessário lembrar que as culturas tradicionais não existem em um mitificado "estado puro"38 que não se articula com o capitalismo dominante ou que sejam "conservacionistas naturais" ${ }^{\prime}$. Ao contrário, essas culturas, como qualquer outra cultura, entram em relações e trocas diante de um mundo intercultural e globalizado, em que há confrontação e entrelaçamento e implica negociação e empréstimos recíprocos ${ }^{39}$.

No entanto, o reconhecimento dos direitos fundamentais das comunidades tradicionais não se assenta na "suposta essência identitária virtualmente existente" ${ }^{\text {"40 }}$, identidade imutável e de práticas consolidadas, mas, sobretudo, na forma como se designam, se reconhecem e se organizam frente às imposições globalizantes e homogeneizantes. Produzir e promover Saúde da Família envolve não somente ocupar espaços com essa fala e ação, mas no processo dessa luta compreender a função formativa dos sujeitos sociais que assumem a produção da saúde coletiva como afirmação dos que no litoral fazem a vida no mar.

\section{Considerações finais}

A institucionalidade do direito à saúde no Brasil é inalienável, uma conquista que a cada tempo se deve efetivar mais amplamente. À parte isso, percebe-se que a saúde é produzida em todos os lugares da vida social e que neles se expressam saberes capazes de dar contexto, concretude e dialogismo aos dos profissionais de saúde. Estamos em um momento sociopolítico em que o princípio de estado, por se aliar ao do mercado, precisa ser limitado pelo princípio de comunidade $e^{41}$ e a ESF tem responsabilidade inadiáveis nesse processo. Trata-se de garantir a diversidade, as formas de vida que, por diferentes contextos, vivenciam o humano com outras potências.

Os povos do mar constituem culturas singulares em que o reconhecimento da autoidentificação à chamada, por eles, de "vida no mar" é o critério legítimo de pertencimento. Suas agendas reivindicatórias surgem num contexto de crise ambiental em que as comunidades periféricas são as que mais sofrem seus efeitos, atônitas ante a precarização de suas condições de vida e, consequentemente, de saúde.

A lógica do capital se insurge, sem, contudo, conseguir anular inteiramente a racionalidade da vida solidária dos povos do mar. As transformações que esses povos vêm vivendo se dão na dialética entre ajustamento e resistência e reverberam significativamente nas suas condições de 
vida, cabendo a ESF atentar aos faróis que clareiam os caminhos da produção da saúde dos povos do mar em fina sintonia com suas singularidades culturais.

\section{Colaboradores}

CP Bezerra trabalhou na concepção, metodologia, pesquisa de campo, análise e redação do artigo. AMB Linhares trabalhou na metodologia, pesquisa de campo, análise, redação e revisão final.

\section{Referências}

1. Brasil. Decreto 6.040, de 7 de fevereiro de 2007. Institui a Política Nacional de Desenvolvimento Sustentável dos Povos e Comunidades Tradicionais. Diário Oficial da União 2007; 8 fev.

2. Cunha MC, Almeida MWB. Quem são as populações tradicionais? [Internet]. Site das Unidades de Conservação no Brasil/Instituto Socioambiental; 2010 [acessado 2020 Mar 19]. Disponível em: https://uc.socioambiental.org.

3. Carneiro FF, Pessoa VM, Teixeira, ACA, organizadores. Campo, Floresta e Águas: práticas e saberes em saúde. Brasília: UNB; 2017.

4. Acselrad H. Conflitos ambientais no Brasil. Rio de Janeiro: Relume Dumará; 2004.

5. Diegues ACS. A sócio-antropologia das comunidades de pescadores marítimos no Brasil. Etnográfica 1999; 3(2):361-375.

6. Gomes HCM. Para Onde Sopram os Ventos? Escola, Vida e Cultura dos Povos do Mar [dissertação]. Fortaleza: Universidade Federal do Ceará; 2002.

7. Lima MC. Comunidades Pesqueiras Marítimas no Ceará: Território, costumes e conflitos [tese]. São Paulo: Universidade de São Paulo; 2002.

8. Diegues ACS. Povos e Mares: Leituras em Sócio-Antropologia Marítima. São Paulo: Nupaub; 1995.

9. Minayo MCS. Contribuições da Antropologia para pensar a saúde. In: Campos GWS, Minayo MCS, Akerman M, Drumond Júnior M, Carvalho YM, organizadores. Tratado de Saúde Coletiva. São Paulo: Hucitec; 2012. p.189-218.

10. Starfield B. Atenção Primária: equilíbrio entre necessidade de saúde, serviços e tecnologias. Brasília: UNESCO/MS; 2002. 
11. Santos MA. A Natureza do Espaço: técnica e tempo. Razão e emoção. São Paulo: Hucitec; 1997.

12. Freire P. Pedagogia da Esperança: um reencontro com a pedagogia do oprimido. Rio de Janeiro: Paz e Terra; 1992.

13. Brasil. As Cartas da Promoção da Saúde. Brasília: MS; 2002.

14. Geertz C. A Interpretação das Culturas. Rio de Janeiro: LTC; 1989.

15. Halbwachs M. A Memória Coletiva. São Paulo: Revista dos Tribunais; 1990.

16. Josso MC. Experiências de Vida e Formação. São Paulo: Cortez; 2004.

17. Benjamin W. Obras escolhidas I- Magia, técnica, arte e política. São Paulo: Brasiliense; 1991.

18. Alves PC. Cultura: múltiplas leituras. Bauru: EDUSC; Salvador: EDUFBA; 2010.

19. Barata RB. Como e por que as desigualdades sociais fazem mal à saúde. Rio de Janeiro: Fiocruz; 2009.

20. Dias LC. Abordagem familiar. In: Gusso G, Lopes JMC. Tratado de Medicina de Família e Comunidade: princípios, formação e prática. Porto Alegre: ArtMed; 2012. p. 221-232.

21. Andrade LOM, Barreto ICHC, Goya N, Martins TJ. Estratégia Saúde da Família em Sobral. Sanare Rev Politicas Públicas 2004; 1(5):9-20.

22. Geistdoerfer A. Anthropologie Maritime: appropriation technique, sociale et symbolique des ressources maritimes. Paris: CNRS; 1989.

23. Diegues ACS. Ilhas e Mares - simbolismo e imaginário. São Paulo: Hucitec; 1998.

24. Diegues ACS. Pescadores, Camponeses e Trabalhadores do Mar. São Paulo: Ática; 1983.

25. Valla VV. Apoio Social e Saúde: buscando compreender a fala das classes populares. In: Costa MV. Educação Popular Hoje. São Paulo: Loyola; 1998. p. 151-179.

26. Turner V. O Processo Ritual: estrutura e antiestrutura. Petropólis: Vozes; 1974.

27. Linhares AMB. O tortuoso e doce caminho da sensibilidade: um estudo sobre a arte e educação. Ijuí: Unijuí; 2003.

28. Tupinambá SV. Do tempo da captura à captura do tempo livre - terra e mar: caminhos da sustentabilidade [dissertação]. Fortaleza: Universidade Federal do Ceará; 1999.

29. Maldonado SC. Mestres e Mares: espaço e indivisão na pesca marítima. São Paulo: AnnBlume; 1993.

30. Brandão CR. O que é Educação. São Paulo: Brasiliense; 1995.

31. Dantas VMA. Dialogismo e arte na gestão em saúde: A perspectiva popular nas cirandas da vida. Porto Alegre: Rede Unida; 2020.
32. Silva MRF. Linhas de cristalização e de fugas nas trilhas da Estratégia Saúde da Família: uma cartografia da micropolítica [tese]. Fortaleza: Universidade Federal do Ceará; 2012.

33. Bezerra CP. Memorial da Redonda: reinvenção e luta na produção da saúde dos povos do mar [dissertação]. Fortaleza: Universidade Federal do Ceará; 2013.

34. Bezerra CP, Linhares AMB. Imaginemos Redonda: reflexões sobre sustentabilidade, buscando o ponto de vista da população. In: Matos KSAL. Educação Ambiental e Sustentabilidade IV. Fortaleza: UFC; 2013. p. 228-245.

35. Céu de Lima M. Pescadoras e pescadores artesanais do Ceará: modo de vida, confrontos e horizontes. Mercator Rev Geo UFC 2006; 5(10):39-54.

36. Sousa MF. A reconstrução da saúde da família no Brasil: diversidade e incompletude. In: Sousa MF, Franco MS, Mendonça AVM. Saúde da Família nos Municípios Brasileiros: os reflexos dos 20 anos no espelho do futuro. Campinas: Saberes; 2014. p. 40-76.

37. Acselrad H, Mello CCA, Bezerra GN. O que é justiça ambiental. Rio de Janeiro: Garamond; 2009.

38. Diegues ACS. O mito moderno da natureza intocada. São Paulo: Hucitec; 2001.

39. Canclini NG. Diferentes, Desiguais e Desconectados: mapas da interculturalidade. Rio de Janeiro: UFRJ; 2009.

40. Brasil. Ministério Público Federal (MPF). Territórios de povos e comunidades tradicionais e as unidades de conservação de proteção integral: alternativas para o asseguramento de direitos socioambientais. Brasília: MPF; 2014.

41. Santos BS. Para um novo senso comum: a ciência, o direito e a política na transição paradigmática. São Paulo: Cortez; 2011.

Artigo apresentado em 06/08/2020

Aprovado em 22/02/2021

Versão final apresentada em 24/02/2021

Editores-chefes: Romeu Gomes, Antônio Augusto Moura da Silva 